\title{
PENGARUH PERCEIVED VALUE, BRAND IMAGE, DAN TRUST TERHADAP LOYALITAS PELANGGAN
}

\author{
Yustinus Ericko Kelvianto \\ Program Studi Magister Manajemen Universitas Tarumanagara \\ yustinuserickok@gmail.com
}

Masuk : 28-05-2019, revisi : 26-08-2019 diterima untuk diterbitkan : 27-08-2019

\begin{abstract}
The purpose of this research is to understand the effect of perceived value, brand image, and trust to Customers' Loyalty. The research design is based on descriptive method and the data was collected through primary data with five Likert-Scales questionaire. The samples of this research are customer who use one of the LCC flight service at least 2 times in 3 months. Convenience sampling method was used in order to gather data. Out of 200 questioners, 167 questioners were computed with SPSS to give the results. This research about The Effect of Perceived Value, Brand Image, and Trust to Customers' Loyalty can be concluded that Customers' loyalty is affected positively by the perceived value, brand image, and trust. Thus, the company should improve their perceived value, brand image, and trust to maintain and increase their customer's loyalty.
\end{abstract}

Abstrak : Tujuan dari penelitian ini adalah untuk memahami pengaruh dari perceived value, brand image, dan trust terhadap loyalitas pelanggan. Rancangan penelitian didasarkan pada metode deskriptif dan data dikumpulkan melalui data primer dengan kuesioner 5 skala Likert. Sampel dari penelitian ini adalah pelanggan salah satu maskapai penerbangan LCC yang menggunakan jasa penerbangan minimal 2 kali selama 3 bulan. Convenience sampling method digunakan dalam pengumpulan data. Dari 200 kuesioner, 167 kuesioner diolah dengan SPSS untuk mendapatkan hasil. Penelitian mengenai pengaruh perceived value, brand image, dan trust terhadap loyalitas pelanggan memberikan hasil bahwa loyalitas pelanggan dipengaruhi secara positif oleh perceived value, brand image, dan trust. Oleh karena itu perusahaan harus mengembangkan perceived value, brand image, dan trust guna mempertahankan dan meningkatkan loyalitas pelanggan mereka.

Keywords : Perceived Value, Brand Image, Trust, Customer Loyalty.

\section{PENDAHULUAN}

Dalam kehidupan masyarakat modern ini, transportasi menjadi salah satu sarana yang tidak dapat dilepaskan peranannya dalam kehidupan sehari-hari. Selain untuk menghemat waktu dan tenaga, penggunaan transportasi juga membantu menjangkau wilayah tujuan jauh serta terbatasnya akses ke wilayah tertentu mengingat Indonesia merupakan Negara kepulauan. Peran penting transportasi diikuti dengan tingginya jumlah pengguna transportasi, baik darat, laut, maupun udara, telah berkembang menjadi industri jasa yang kompetitif.

Jasa transportasi diharapkan mampu mempercepat mobilitas pengguna di tingkat penduduk heterogen dan arus lalu lintas yang padat ketika bepergian antar kota atau bahkan antar pulau. Selain itu, faktor pelayanan dan kenyamanan di perjalanan juga menjadi perhatian pengguna jasa transportasi. Salah satu industri jasa transportasi yang memenuhi kriteria pelayanan ini adalah industri penerbangan.

Kebutuhan dan kekuatan pelanggan dalam menggunakan dan memilih layanan transportasi udara telah meningkatkan kompetisi industri tersebut. Setiap perusahaan transportasi udara berusaha untuk bersaing mempertahankan dan meningkatkan pangsa pasar demi kelangsungan bisnisnya secara jangka panjang dengan menargetkan pelanggan sebagai 
sumber penghasilan perusahaan. McDougall dan Levesque (2000) mengungkapkan bahwa loyalitas pelanggan menjadi penentu utama keberhasilan kompetisi perusahaan.

Menurut Chinomona (2016), loyalitas pelanggan menjadi kepuasan pelanggan atas performa produk atau jasa yang diterimanya. Brunner et al. (2018) menyatakan pelanggan yang loyal memiliki intensi merekomendasikan produk atau jasa kepada orang lain dan loyalitas pelanggan yang tinggi akan semakin meningkatkan profit perusahaan. Kuusik (2017), Trassoras et al. (2009), dan Li (2013), mengungkapkan beberapa faktor seperti perceived value, brand image, dan trust dapat menjelaskan perubahan loyalitas pelanggan.

Menurut Pura (2005), perceived value menjadi penilaian pelanggan atas apa yang diterima relatif terhadap yang diberikan. Penelitian oleh Ishaq (2011) serta Javed dan Cheema (2017) menunjukkan bahwa perceived value memotivasi pelanggan untuk loyal terhadap produk atau jasa sehingga mempengaruhi loyalitas secara signifikan positif.

Menurut Bauer et al. (2005), brand image merupakan produk kumulatif dari asosiasi brand dalam pikiran pelanggan. Penelitian yang dilakukan oleh Bauer et al. (2005) menunjukkan bahwa ketika pelanggan terikat pada suatu brand spesifik atas atribut, manfaat, dan kesenangan yang memuaskannya, maka pelanggan akan loyal. Pada akhirnya, brand image berpengaruh signifikan positif terhadap loyalitas.

Berdasarkan Chinomona (2016), trust menunjukkan kepercayaan pelanggan atas performa produk atau jasa yang memberikan kepuasan sesuai dengan harapan pelanggan. Pada penelitian Mishra dan Kesharwani (2018), trust yang tinggi menunjukkan keyakinan pelanggan untuk membeli kembali dan meningkatkan volume pembelian produk atau jasa tersebut sehingga pelanggan menjadi loyal. Penelitian oleh Ribbink et al. (2004) menghasilkan trust secara positif dan signifikan mempengaruhi loyalitas.

Tujuan dari penelitian ini adalah untuk mengetahui pengaruh perceived value, brand image, dan trust terhadap loyalitas pelanggan.

\section{LANDASAN TEORI}

McDougall dan Levesque (2000: 394) menjelaskan "perceived value is the results or benefits customers receive in relation to total costs (which include the price paid plus other costs associated with the purchase)." Oleh karena itu, perceived value dapat diartikan sebagai perbandingan antara total nilai yang diterima pelanggan dari suatu produk atau jasa dengan apa yang dibayarkan pelanggan.

Bauer et al. (2005: 10) menyatakan "Brand image is defined as the cumulative product of brand associations in the consumer's mind." Dengan demikian, brand image merupakan keseluruhan asosiasi brand dalam mental pelanggan akan suatu produk atau jasa sehingga menimbulkan persepsi atas produk atau jasa tersebut.

Chinomona (2016: 127) menjelaskan "trust can be defined as the extent to which a consumer believes that a certain brand he or she has confidence in satisfies his or her desire." Jadi, trust adalah keyakinan pelanggan akan segala janji yang akan diperoleh dari suatu produk atau jasa yang sesuai dengan harapan pelanggan.

Dolarslan (2014: 709) mendefinisikan "loyalty is described as a deeply held commitment to rebuy or repatronize a preferred product/service consistently in the future, thereby causing repetitive same-brand or same brandset purchasing, despite marketing efforts to case 'switching behavior'." Dari uraian tersebut, peneliti menyimpulkan loyalitas pelanggan sebagai komitmen pelanggan untuk berlangganan ataupun melakukan pembelian kembali karena kesesuaian penawaran produk atau jasa yang diterima dengan ekspektasi pelanggan.

\section{Pengaruh Perceived Value terhadap Loyalitas Pelanggan}

Yang dan Peterson (2004) mengungkapkan bahwa perceived value merupakan kunci penggerak loyalitas pelanggan dan menjadi prediktor kuat loyalitas pelanggan. Merujuk Javed dan Cheema (2017), perceived value yang baik bermanfaat menarik perhatian pelanggan, 
mengembangkan, serta menjaga hubungan baik dengan pelanggan untuk mencapai loyalitas. Pengaruh positif dari perceived value terhadap loyalitas pelanggan juga dinyatakan oleh Ishaq (2011) dimana perceived value merupakan antiseden dari loyalitas dengan mendorong keunggulan kompetitif dan keberhasilan perusahaan. Ketika perceived value meningkat, loyalitas pelanggan secara konsisten juga meningkat. Berdasarkan uraian tersebut, hipotesis penelitian $\left(\mathrm{H}_{1}\right)$ adalah:

$\mathrm{H}_{1}$ : Perceived value berpengaruh positif terhadap loyalitas pelanggan

\section{Pengaruh Brand Image terhadap Loyalitas Pelanggan}

Menurut Chinomona (2016), brand image menjadi alasan pelanggan untuk terikat menggunakan dan menentukan keputusan pembelian produk atau jasa. Bauer et al. (2005) mengungkapkan brand image sebagai anteseden loyalitas dimana pelanggan semakin loyal dalam menggunakan produk atau jasa jika brand image yang dimiliki kuat sehingga brand image menjadi faktor penting loyalitas pelanggan yang semakin tinggi. Hal sama juga dinyatakan oleh Ogba dan Tan (2009) yang menunjukkan ada pengaruh positif brand image terhadap loyalitas pelanggan. Oleh karena itu, ditarik hipotesis penelitian $\left(\mathrm{H}_{2}\right)$ adalah :

$\mathrm{H}_{2}$ : Brand image berpengaruh positif terhadap loyalitas pelanggan

\section{Pengaruh Trust terhadap Loyalitas Pelanggan}

Ribbink et al. (2004) menjelaskan bahwa trust merupakan penentu awal untuk berlangganan dan berperan penting dalam mengembangkan serta mempertahankan hubungan jangka panjang dengan pelanggan. Trust yang dibentuk dari pengalaman masa lalu dapat secara langsung mempengaruhi loyalitas, terutama ketika resiko tinggi. Menurut Vuuren et al. (2012), trust penting terhadap loyalitas. Hal yang sama juga didukung oleh Damtew dan Pagidimarri (2013) dimana semakin tinggi trust maka loyalitas juga semakin meningkat. Maka, ditarik hipotesis $\left(\mathrm{H}_{3}\right)$ :

$\mathrm{H}_{3}$ : Trust berpengaruh positif terhadap loyalitas pelanggan

\section{METODOLOGI}

Populasi dan Metode Pengambilan Sampel. Populasi dalam penelitian ini adalah seluruh pelanggan salah satu maskapai penerbangan LCC. Ukuran sampel yang digunakan dalam penelitian ini adalah 167 orang. Metode pengambilan sampel adalah non-probability sampling dengan teknik pengambilan sampel convenience sampling. Berdasarkan data yang terkumpul, profil mayoritas responden berjenis kelamin perempuan sebesar 59,9\%, berdomisili di luar Jakarta sebesar $43,7 \%$, berusia $\leq 20$ tahun sebesar $31,7 \%$, dan berpendidikan terakhir S1 sebesar $41,9 \%$. Sebagian besar responden mengetahui salah satu maskapai penerbangan LCC pertama kali dari media elektronik sebesar 38,3\% dan menggunakan jasa maskapai salah satu maskapai penerbangan LCC dengan rute penerbangan domestik sebesar 71,9\%.

Variabel dan Pengukuran. Dalam penelitian ini terdapat 3 variabel bebas (perceived value, brand image, dan trust) dan 1 variabel terikat (loyalitas pelanggan). Skala pengukuran yang digunakan adalah Skala Likert 5 poin dengan 1 menunjukkan "sangat tidak setuju" dan 5 menunjukkan "sangat setuju". Hasil uji validitas dan reliabilitias menunjukkan bahwa semua variabel yang digunakan dalam penelitian ini adalah valid dan reliabel. Tabel berikut menunjukkan pengukuran masing-masing variabel dan sumbernya : 
Tabel 1. Variabel dan Pengukuran

\begin{tabular}{l|c|l}
\hline \multicolumn{1}{c|}{ Variabel } & Jumlah Item & \multicolumn{1}{c}{ Sumber } \\
\hline $\begin{array}{l}\text { Variabel Bebas } \\
\text { 1. Perceived Value }\end{array}$ & 5 & $\begin{array}{l}\text { Trassoras } \text { et al. (2009), } \\
\text { Roig et al. (2006) } \\
\text { Seftiani (2014), Fianto } \text { et } \\
\text { al. (2014) } \\
\text { Rai dan Medha (2013), Neij } \\
\text { dan Martensson (2013), } \\
\text { Leninkumar (2017) }\end{array}$ \\
3. Trust & 5 & $\begin{array}{l}\text { Yarmen (2017), Neij dan } \\
\text { Martensson } \\
\text { Auruskeviciene et al. } \\
\text { (2010) }\end{array}$ \\
\hline $\begin{array}{l}\text { Variabel Terikat } \\
\text { 1. Loyalitas Pelanggan }\end{array}$ & 4 &
\end{tabular}

Metode Analisis Data. Pada penelitian ini, uji asumsi klasik yang digunakan terdiri dari uji normalitas, uji multikolinieritas dan uji heteroskedastisitas. Hasil uji ke-3nya menunjukan semua uji asumsi terpenuhi. Metode analisis data yang digunakan berupa analisis regresi ganda. Pengujian dalam penelitian ini menggunakan program SPSS dengan taraf signifikansi penelitian adalah 0,05 .

\section{ANALISA DAN PEMBAHASAN}

Tabel 2. Hasil Pengujian Hipotesis

\begin{tabular}{|lllccc|}
\hline \multicolumn{3}{|c}{ Hipotesis } & B & Sig. & Kesimpulan \\
\hline $\mathrm{H}_{1}$ & $\begin{array}{l}\text { Perceived value berpengaruh positif terhadap } \\
\text { loyalitas pelanggan. }\end{array}$ & 0,241 & 0,000 & Tidak Ditolak \\
$\mathrm{H}_{2}$ & $\begin{array}{l}\text { Brand image berpengaruh positif terhadap } \\
\text { loyalitas pelanggan. }\end{array}$ & 0,244 & 0,001 & Tidak Ditolak \\
$\mathrm{H}_{3} \begin{array}{l}\text { Trust berpengaruh positif terhadap loyalitas } \\
\text { pelanggan. }\end{array}$ & 0,505 & 0,000 & Tidak Ditolak \\
\hline
\end{tabular}

Hipotesis pertama digunakan untuk menguji apakah perceived value berpengaruh positif terhadap loyalitas pelanggan. Berdasarkan hasil rekapitulasi hipotesis, dapat diketahui perceived value berpengaruh positif terhadap loyalitas pelanggan. Hal ini sesuai dengan Yang dan Peterson (2004) yang mengungkapkan perceived value menjadi kunci penggerak dan prediktor kuat terhadap loyalitas pelanggan. Tujuan pelanggan menggunakan maskapai penerbangan LCC adalah untuk pergi ke tempat tujuan melalui jalur udara dengan harga yang lebih terjangkau dan salah satu maskapai penerbangan LCC sudah memberikan total nilai yang sesuai dengan apa yang dibayarkan bagi pelanggan.

Hipotesis kedua adalah untuk menguji apakah brand image berpengaruh positif terhadap loyalitas pelanggan. Hasil pengujian hipotesis menemukan bahwa brand image berpengaruh positif terhadap loyalitas pelanggan sehingga hasil sesuai dengan Bauer et al. (2005) yang mengungkapkan brand image sebagai anteseden loyalitas dimana pelanggan semakin loyal menggunakan produk atau jasa jika brand image kuat sehingga brand image menjadi faktor penting penyebab loyalitas pelanggan semakin tinggi. Salah satu maskapai penerbangan LCC memiliki brand yang kuat karena merupakan maskapai jasa penerbangan pertama dengan 
keunggulan kompetitif bertarif murah dan sudah lama berdiri. Maskapai juga melayani banyak rute penerbangan (183 rute) hingga ke pelosok negeri dengan jumlah armada yang besar.

Hipotesis ketiga menguji apakah trust berpengaruh positif terhadap loyalitas pelanggan.

Hasil menunjukkan trust berpengaruh positif terhadap loyalitas pelanggan dan sudah sejalan dengan Damtew dan Pagidimarri (2013) dimana semakin tinggi trust maka loyalitas juga semakin meningkat. Salah satu maskapai penerbangan LCC membantu pelanggan merasakan pengalaman bepergian lewat udara dengan harga relatif terjangkau dan menjadi tujuan utama pelanggan menggunakan jasa maskapai udara. Dalam penelitian ini, kuatnya variabel trust dalam kasus loyalitas pelanggan menunjukkan bahwa variabel ini sangat penting agar pelanggan melakukan pembelian berulang secara jangka panjang.

Dari semua hasil pengujian hipotesis, dapat disimpulkan bahwa hipotesis untuk variabel perceived value, brand image, dan trust berpengaruh positif terhadap loyalitas pelanggan tidak ditolak.

\section{PENUTUP}

Kesimpulan. Dalam menjalankan suatu bisnis, suatu perusahaan harus mampu bersaing dengan kompetitornya agar dapat bertahan dalam jangka panjang. Salah satu cara mewujudkannya adalah dengan menjaga loyalitas pelanggan. Loyalitas pelanggan yang terjaga akan membuat pelanggan tetap membeli produk atau jasa perusahaan secara berkelanjutan sehingga perusahaan tetap hidup dan kompetitif. Beberapa faktor yang mempengaruhi loyalitas pelanggan secara signifikan, seperti perceived value, brand image, dan trust perlu menjadi fokus perusahaan.

Penelitian ini menunjukkan bahwa perceived value, brand image, dan trust berpengaruh positif terhadap loyalitas pelanggan salah satu maskapai penerbangan LCC. Jika pelanggan mendapatkan persepsi nilai yang sesuai dengan harapannya, maka pelanggan akan semakin loyal. Perusahaan juga harus memberikan persepsi jasa yang baik dari seluruh kumulatif asosiasi brand dalam ingatan pelanggan agar perusahaan memiliki gambaran yang baik dan pada akhirnya pelanggan menjadi loyal. Selain itu, loyalitas pelanggan juga akan semakin meningkat jika perusahaan dapat memenuhi janji jasa sesuai dengan harapan pelanggan agar pelanggan terus berkomitmen untuk menggunakan kembali jasa perusahaan tersebut.

Saran. Untuk menjaga loyalitas pelanggan, salah satu maskapai penerbangan LCC dapat meningkatkan perceived value, brand image, dan trust pelanggan terhadap perusahaannya. Guna meningkatkan perceived value, perusahaan dapat meningkatkan nilai pelayanan personilnya agar lebih sigap, terampil, dan perhatian dalam melayani pelanggannya ataupun dengan menyediakan promo khusus bagi pelanggan setianya, seperti bagasi gratis. Brand image dapat ditingkatkan dengan melakukan kegiatan periklanan atau update event dan promo penting secara konsisten, potongan harga tiket seat tertentu dengan destinasi yang populer dikunjungi, serta merekrut orang-orang yang aktif juga memiliki banyak koneksi di media sosial sebagai karyawannya ataupun menjadikan pelanggan sebagai brand ambassador perusahaan. Perusahaan dapat meningkatkan trust melalui komitmen penuh dalam menghilangkan delay, merawat armada secara berkala guna menghindari kendala teknis atau kecelakaan, serta meningkatkan pelatihan personilnya. Bagi peneliti selanjutnya, diharapkan dapat menambahkan variabel lain yang tidak tercakup pada penelitian ini namun berpeluang menjadi faktor pengaruh terhadap loyalitas pelanggan. Peneliti selanjutnya juga diharapkan dapat melakukan penelitian bukan dari sudut pandang pelanggan saja, namun juga dari internal perusahaan. 


\section{DAFTAR PUSTAKA}

Bauer H., Sauer N., Exler S. (2005). The Loyalty of German Soccer Fans: Does a Team's Brand Image Matter?. International Journal of Sports Marketing and Sponsorship, 7 (1), 8-16.

Chinomona R. (2016). Brand Communication, Brand Image and Brand Trust as Antecedents of Brand Loyalty in Gauteng Province of South Africa. African Journal of Economic and Management Studies, 7 (1), 124-139.

Damtew K., Pagidimarri V. (2013). The Role of “Trust” in Building Customer Loyalty in Insurance Sector-A Study. IOSR Journal of Business and Management, 14 (4), 82-93.

Donio J., Massari P., Passiante G. (2006). Customer Satisfaction and Loyalty in A Digital Environment: An Empirical Test. Journal of Consumer Marketing, 23 (7), 445-457.

Ishaq M. (2011). Perceived Value, Service Quality, Corporate Image and Customer Loyalty : Empirical Assessment from Pakistan. Serbian Journal of Management, 7 (1), 25-36.

Javed F., Cheema S. (2017). Customer Satisfaction and Customer Perceived Value and Its Impact on Customer Loyalty: The Mediational Role of Customer Relationship Management. Journal of Internet Banking and Commerce, 22 (S8), 1-14.

McDougall G., Levesque T. (2000). Customer Satisfaction with Services: Putting Perceived Value into The Equation. Journal of Services Marketing, 14 (5), 392-410.

Melewar T., Foroudi P., Gupta S., Kitchen P., Foroudi M. (2018). Integrating Identity, Strategy, and Communications for Trust, Loyalty and Commitment. European Journal of Marketing, 51 (3), 572-604.

Ogba I., Tan Z. (2009). Exploring The Impact of Brand Image on Customer Loyalty and Commitment in China. Journal of Technology Management in China, 4 (2), 132-144.

Plasmeijer P., Raaij W. (2017). Banking System Trust, Bank Trust, and Bank Loyalty. International Journal of Bank Marketing, 35 (1), 97-111.

Ribbink D., Riel A., Liljander V., Streukens S. (2004). Comfort Your Online Customer : Quality, Trust and Loyalty on The Internet. An International Journal, 14 (6), 445-456.

Vuuren T., Lombard M., Tonder E. (2012). Customer Satisfaction, Trust and Commitment As Predictors of Customer Loyalty within An Optometric Practice Environment. Southern African Business Review, 16 (3), 81-96.

Yang Z., Peterson R. (2004). Customer Perceived Value, Satisfaction, and Loyalty: The Role of Switching Costs. Psychology \& Marketing, 21 (10), 799-822. 